\title{
An experimental case of wood-working use-wear on quartzite artefacts
}

\author{
Ji-Ying Liu ', Hong Chen ${ }^{1,2}$ \\ 1 Institute of Cultural Heritage and Museology, Zhejiang University, Hangzhou, CN \\ 2 Department of Cultural Heritage and Museology, Zhejiang University, Hangzhou, CN \\ 317092107@qq.com
}

\begin{abstract}
Use-wear analysis has become an essential method for the functional study of lithic artefacts from prehistoric archaeological assemblages. On the basis of earlier research, this article discusses experiments and analyses of use-wear on quartzite artefacts caused by wood-working. The raw materials of the artefacts were collected from the Wulanmulun Site, Inner Mongolia. The woodworking techniques include scraping, drilling, and chopping. Scarring sizes are mostly medium and small. Scarring terminations are mainly feathered; stepped terminations are caused by scraping and chopping wood. Scarring mainly appears as run-together distributions. Medium and heavy rounding is found on the edges of the artefacts.
\end{abstract}

IZVLEČEK - Analiza sledov uporabe je postala ključna metoda za prepoznavanje funkcij kamnitih orodij iz prazgodovinskih artefaktnih zbirov. Na osnovi starejših raziskav $v$ članki razpravljamo $o$ eksperimentih in analizah uporabe artefaktov iz kvarcita, ki so bili uporabljeni pri obdelavi lesa. Surovino za takšna orodja so v prazgodovini nabirali na najdišč Wulanmulun na območju Notranje Mongolije. Tehnike obdelave lesa vključujejo strganje, vrtanje in sekanje. Poškodbe na orodjih so večinoma srednje do majhne. Brazgotinaste poškodbe so v obliki peresa; stopničaste poškodbe je povzročilo strganje in sekanje lesa. Brazgotinaste poškodbe se pojavljajo v glavnem porazdeljene v skupine. Na orodjih smo prepoznali tudi srednje do močno zarobljenje roba delovne površine.

KEY WORDS - quartzite artefacts; wood-working; replicative experiment; use-wear analysis

\section{Introduction}

Based on experimental observations, use-wear analysis refers to the study of wear traces on the edge or surface of artefacts caused by use (e.g., Fullagar, Matherson 2013; Odell 2004). It has been widely accepted that use-wear analysis is an important way to identify, classify and compare wear traces, which allow functional interpretations and reconstructions of human behaviour (e.g., Redman 1973; Marreiros et al. 2015).

Low- and high-power magnifications are two methods that contribute to recognising use wear and functional interpretation (e.g., Odell 1977; Keeley 1980). Low-power magnification primarily follows Semenov's (1964) methodology of using a stereoscopic microscopy. This low-power approach, focusing main- ly on microfractures and abrasion, such as edge damage, rounding, and diagnostic fractures, has an advantage over the observation and analysis of a large number of artefacts.

Quartzite is a non-foliated metamorphic rock containing more than $75 \%$ quartz. It can form sharp edges, and is suitable for tools due to its hardness, rigidity, and medium-grained texture. Use-wear analysis on quartzite artefacts began in the late 1970s (e.g., Toll 1978; Christian 1978), but developed slowly, since quartzite is difficult to observe and analyse under the microscope. In recent years, with methodological and technological developments, quartzite has become one of the most popular materials to study among use-wear researchers. Some replicative expe- 
riments have been conducted by Chinese researchers, but these are still far from enough to support the archaeological interpretation.

In many Paleolithic sites in China, quartzite was an important raw material widely used by early humans. The Wulanmulun site, located in Inner Mongolia, is a typical Paleolithic site where quartzite was the main raw material among the archaeological objects. Since its first excavation in 2010, large quantities of quartzite artefacts have been unearthed (e.g., Hou et al. 2012; Wang et al. 2012). According to the evidence of use wear and hafting wear features observed on some quartzite tools from former functional studies (e.g., Chen et al. 2014), some tools from this site were used for woodworking.

However, previous studies of use-wear often focused on flints and obsidian (e.g., Wang 1992; Li 1992; Hou 1992; Shen, Chen 2001; Chen 2008; Fang 2009). We hope this experimental study may contribute a partial set of reference standards for constructing use-wear patterns on quartzite tools and aid interpretations of archaeological assemblages on the basis of the low-power technique.

\section{Experimental programme}

The aim of this experimental study is to summarise the identifiable use-wear features and patterns under various working techniques and use intensity, and subsequently to enrich the comparative reference collection that can be used in functional interpretations of archaeological assemblages.

\section{Experimental design}

Five flakes and one core, both unretouched and with usable edges, were selected for the replicative experiment; some of them have sharp working edges. All of the experimental specimens, produced by hardhammer percussion technique, were made from quartzite nodules collected from Locality 10 at the
Wulanmulun site. The nodules are in three colours: tawny, henna, and black; tawny and henna quartzite consists of much larger grains than black pieces. In order to make the results of the experiment more precise, we collected the supposed contact materials from the Wulanmulun site and local areas. Considering the probable tasks carried out on both fresh and dry wood by prehistoric humans, three working techniques were determined: scraping, drilling, and chopping.

All of the specimens were observed with the low-power technique with an Olympus SZX16 stereoscopic microscope at magnifications ranging from $8.75 \times$ to $143.75 \times$. Typical use-wear patterns were photographed using a Nikon EOS 600D digital camera, and the photos were processed by image processing software.

\section{Analytical items}

The use of a stone tool usually results in two major types of microscopic wear: microfractures and abrasion. Microfracture mainly refers to scarring, including: (1) scarring size; scars can be defined as large (visible at less than 10×), medium (10-20×), small (20-40×), and tiny (above 40×); (2) scarring termination (Fig. 1), classified as feather, hinge, step and snap; and (3) scarring distribution (Fig. 2), which is divided into continuous, uneven, scattered and overlapped. Abrasion includes rounding, polish and striation, while polish can be observed only at high magnification. The three degrees of rounding are heavy, medium and light. Striations, the orientation of which is closely associated with the working technique, can usually be observed under low magnifications.

\section{Experimental process}

During the preparation stage, all of the basic information of each specimen was recorded accurately before use, including raw material colours, morphological characteristics and edge shapes. In order to record areas with use-wear, every specimen was

\begin{tabular}{|lcccccccc|}
\hline $\begin{array}{l}\text { Working } \\
\text { motion }\end{array}$ & $\begin{array}{c}\text { Contact } \\
\text { material }\end{array}$ & Specimen & Type & $\begin{array}{c}\text { Employed } \\
\text { edge shape }\end{array}$ & $\begin{array}{c}\text { Employed } \\
\text { edge length } \\
\text { /mm }\end{array}$ & $\begin{array}{c}\text { Max } \\
\text { length } \\
\text { /mm }\end{array}$ & $\begin{array}{c}\text { Max } \\
\text { width } \\
\text { /mm }\end{array}$ & $\begin{array}{c}\text { Max } \\
\text { thickness } \\
\text { /mm }\end{array}$ \\
\hline Scrape & Fresh poplar & 12EKAC6:81.1 & Flake & Convex edge & 13.9 & 27.4 & 21.2 & 3.5 \\
\hline Scrape & Fresh poplar & C15:1.2 & Flake & Straight edge & 24 & 25.4 & 21.9 & 4.8 \\
\hline Drill & Fresh poplar & AC5:19.1 & Flake & Tip & - & 25.8 & 16.7 & 8 \\
\hline Drill & Fresh poplar & BC7:5.2 & Flake & Tip & - & 41.5 & 30.3 & 9.9 \\
\hline Chop & Dry willow & 12EKBC7-1 & Core & Convex edge & 15.1 & 63.7 & 54.6 & 37.5 \\
\hline Chop & Dry willow & BC7:9.1 & Flake & Straight edge & 19 & 54.8 & 66.3 & 19.5 \\
\hline
\end{tabular}

Tab. 1. Basic information on the experimental specimens. 


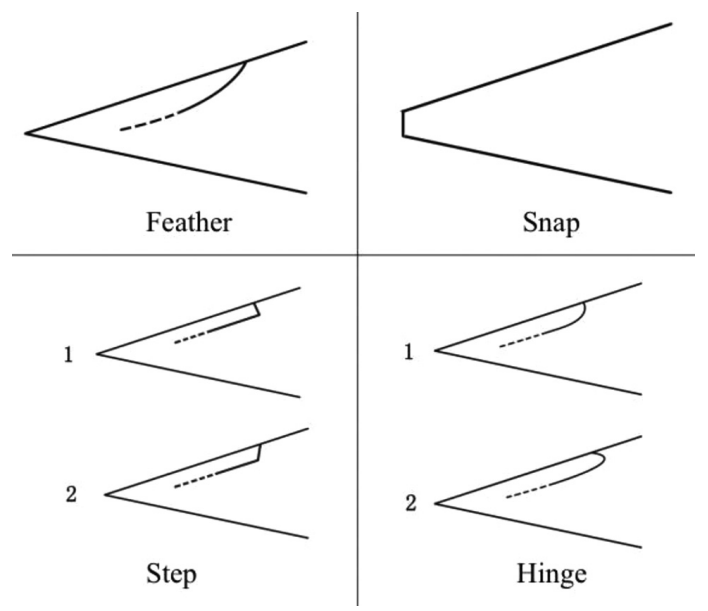

Fig. 1. Scarring termination (after Ho Ho Committee 1979).

sketched and photographed, using the 8-polar coordinate grid defined by George H. Odell (1977). To make it easier to detect change in working edges after use, we painted some white pigment on the working edges of the specimens before use, and then observed and photographed them under a microscope.

As a controlled experiment, each specimen must be used by one particular experimenter in the same working location, with the same working technique, applying the same amount of force. On the basis of some previous experiments we carried out (e.g., Chen 2008; Chen et al. 2015), the total operating time of each specimen was limited to about 15 minutes. Furthermore, to ensure that the experimenters could apply speed and force to relatively the same degree, they had to stop every 3 minutes and record the required information. The experiment was stopped when the specimen became badly damaged.

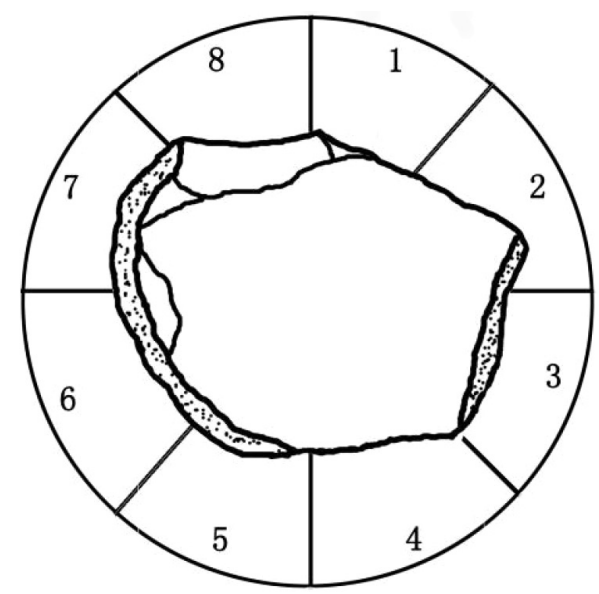

Fig. 3. 8-polar coordinate grid (modified from Odell 1977).

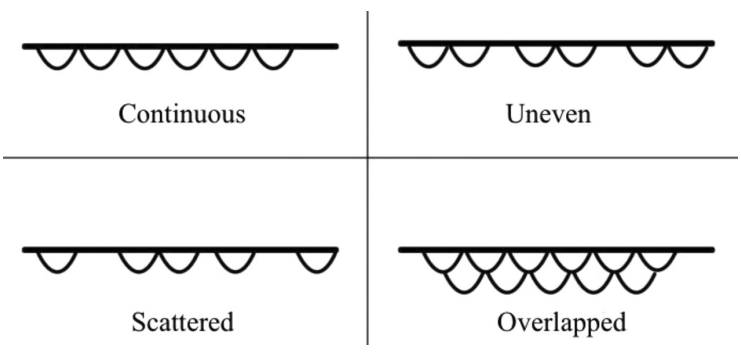

Fig. 2. Scarring distribution.

During the experiment, the working technique of the experimenters on every specimen was recorded in detail, including length, frequency, and time consumed and number of movements of each action (Fang 2009). Action length refers to the distance we worked on the contact material each time. Action frequency is equal to the number of movements in a given time (generally counted in minutes), which reflects the continuity and intensity of each technique. Time consumption means the total time of each experiment. Movement number refers to the total number of times each working action was taken during the experiment.

\section{Experimental results}

Three working techniques were involved in this experimental programme: scraping, drilling and chopping; two specimens were used to perform each technique. The result of the experiments is described below.

\section{Wood-scraping experiment and its use-wear features}

Specimen 12EKAC6:81.1 was used to scrape fresh poplar branch for 15 minutes; action frequency was limited to 511 times per minute. Medium rounding was observed along its edge ridge. Some half-moonshaped notches and several stepped scars appeared along both sides of the working edge. Also, small feather scars were scattered continuously on its dorsal side, and medium feather scars with small feather scars nested inside clustered on its ventral side (Fig. 4).

Specimen C15:1.2 was used for the same task; action frequency was 351 times per minute. Medium rounding can also be observed on its edge ridge. The scars distributed along both sides of the working edge are mainly small feather and step scars. Feather scars appeared more on the ventral than on the dorsal side. It can be seen that scars cross irregularly from the dorsal to the ventral side, appearing in a halfmoon shape seen from the dorsal side. 
No visible modification was found on the two specimens during the experimental process. Use-wear resulting from scraping the fresh poplar branch consisted mainly of small and medium feather scars, with a few stepped scars. The feather scars were mainly distributed continuously on both sides of the working edge. Scars crossing the edge ridge are apparent, appearing in a half-moon shape from the top of the edge. Medium rounding appeared on both specimens after use.

\section{Wood-drilling experiment and its use-wear features} Specimen AC5:19.1 was used to drill a fresh poplar branch in a clockwise rotation for 15 minutes; action frequency was 52 times per minute. The

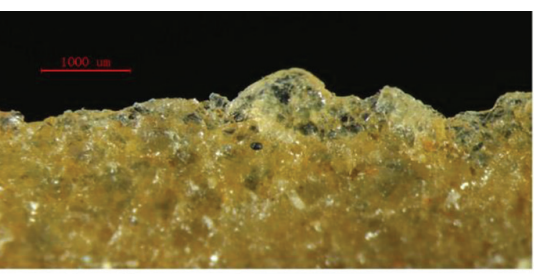

a. D20X (before use)

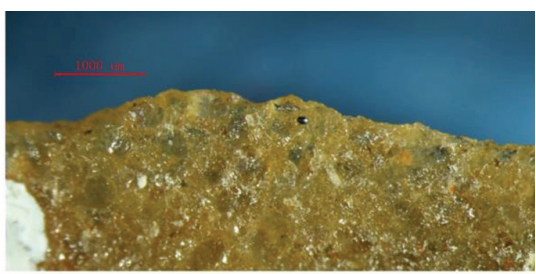

b. D20X(after use)

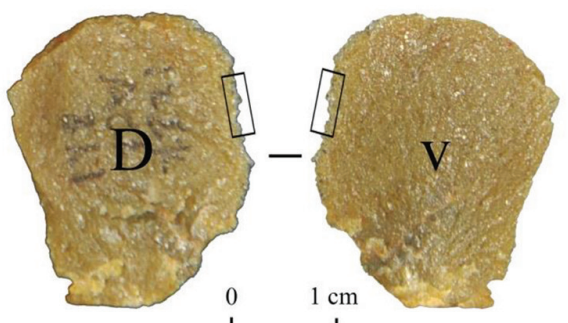

c. V20X (before use)

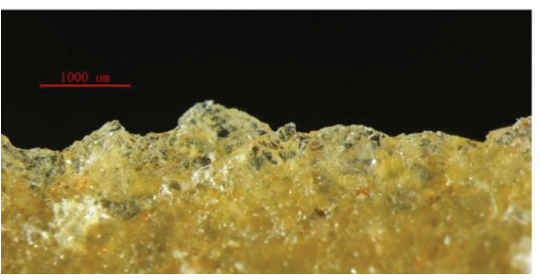

d. V20X(after use)

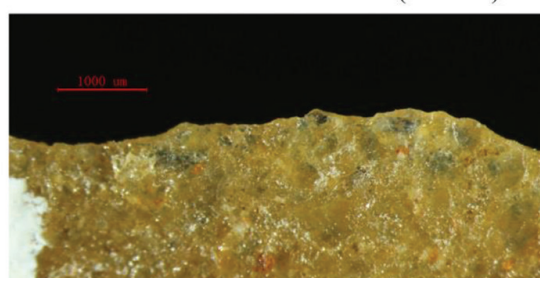

Fig. 4. Use-wear on specimen 12EKAC6:81.1 for scraping wood. a, c No traces. b Half-moon-shaped notches continuously distributed on the dorsal side, with a few small feather scars. d Heavy rounding and a notch appeared on the ventral side of the working edge.

tip and the right working edge became dull, and heavy rounding appeared after use. Small feather scars were observed on the tip, while medium feather scars in continuous distribution were observed on both sides of the right edge. The right edge became denticulate, and small feather scars were distributed on the other working edge.

Specimen BC7:5.2 was used to drill a fresh poplar branch with bidirectional rotation. The experiment lasted only 3 minutes due to the severe damage caused to the specimens. Action frequency was 59 times per minute. Small feather scars and a large crack where several small feather scars were distributed were observed along the edge ridge. Small feather scars were scattered irregularly on the left side of the tip.

The two specimens were used efficiently to drill the wood. The use-wear on the working edge consists mainly of continuously distributed smallmedium feather scars. Heavy rounding was observed on the tip, being more marked on the wood drilled with bidirectional rotation.

\section{Wood-chopping experiment and its use-wear features}

Specimen BC7:9.1 was used to chop dry willow for 13 minutes; action frequency was approx. 96 per minute. Medium rounding appeared on both the working edge's dorsal side and its ridge. Small and medium scars on the dorsal side mainly appeared as feather termination, with a few stepped termina-

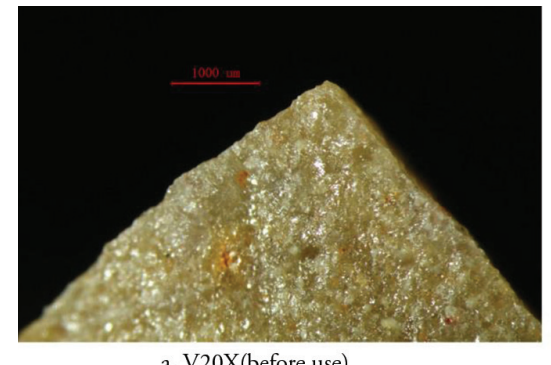

a. V20X(before use)

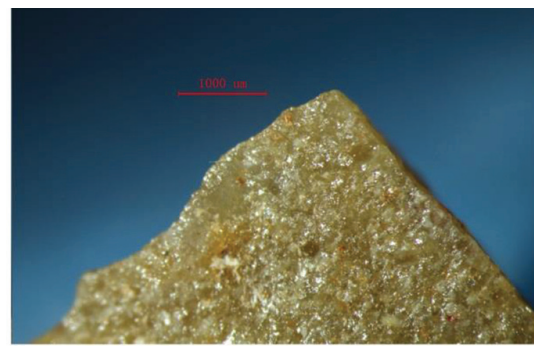

b. V20X (after use)

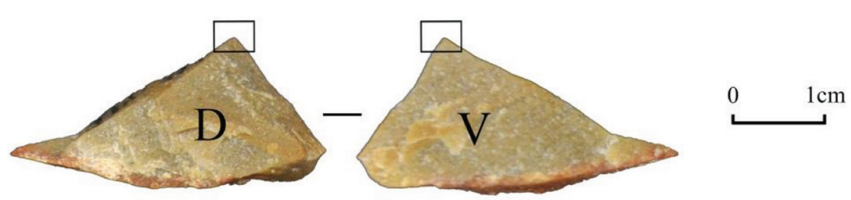

Fig. 5. Use-wear on specimen AC5:19.1 for drilling wood. a No traces. b Heavy rounding appeared on the tip, and medium feather scars were distributed on the working edge. 


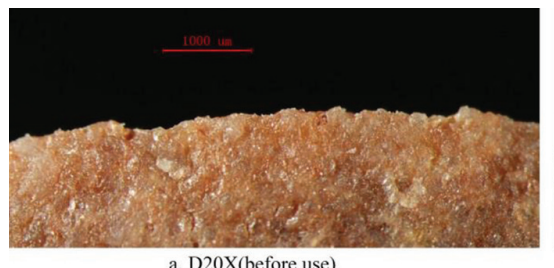

a. D20X(before use)

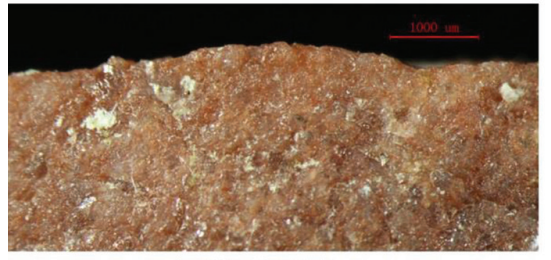

b. D20X(after use)

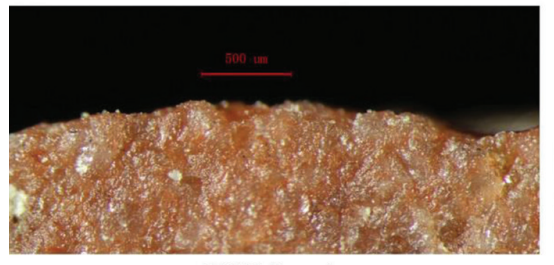

c. D40X(after use)
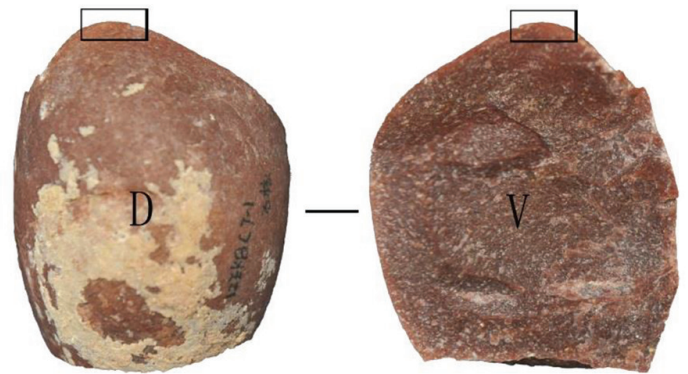

Fig. 6. Use-wear on specimen 12EKBC7-1 for chopping wood. a, d No traces. b Small scars unevenly distributed on the dorsal side, with mainly feather and step terminations. c Small feather scars continuously distributed on the working edge, with a few step scars. e Medium scars, most with step and feather terminations. f Feather scars crossing the edge ridge scattered irregularly on the ventral side.

tions. Several small scars were nested in medium scars. Small feather scars and the starting point of crossed scars were distributed irregularly on the ventral edge.

Specimen 12EKBC7-1 was used for the same task for over 15 minutes. Action frequency was 73 times per minute. Individual small scars crossing from the dorsal to ventral side were observed on the edge ridge. Small scars were scattered continuously along the dorsal edge, most having feather terminations and a few stepped terminations. Medium scars were distributed continuously on the ventral side (Fig. 6).

The chopping efficiency of these two specimens is relatively high. Use-wear caused by chopping is visible to the naked eye, and is most evident in heavy rounding and medium-to-small scars in a continuous distribution. Most scars appear to be feather and stepped terminations, with a few scars crossing the two sides.

\section{Discussion and summary}

Theoretically and experimentally, the mechanical damage to the raw materials of lithic artefacts differed, because the composition and grains are different. Flint, obsidian and quartzite are common raw materials at prehistoric sites, so it is necessary to compare the similarities and differences between use-wear features and patterns from woodworking on raw materials based on experimental studies.

\section{Use-wear features caused by wood-working on quar- tzite artefacts}

The experimental results show that micro-wear was caused by wood-working activities. Some preliminary conclusions about use-wear features and patterns caused by wood-working can be indicated.

The distribution of micro-fracture damage on the working locations may somehow be affected by various working techniques. With the same technique, different specimens display similar sizes, terminations and distribution of scars. However, use-wear features may vary due to occasional factors during experiments. It is a distinct feature that working edges became dull after scraping wood. Most of the scars are distributed continuously; most have feather terminations, with a few step and rolled-over terminations. On the other hand, the specimens' edges became smoother after chopping wood; continuously scattered medium and small scars can be observed. Compared with wood scraping, step and rolled-over shaped terminations were observed much more on the working edge. After drilling wood, the tips of the specimens cracked, and only feather scars appeared.

The rounding which appeared on the quartzite artefacts after wood-working is obvious, and is main- 


\begin{tabular}{|c|c|c|c|c|}
\hline \multicolumn{2}{|c|}{ Comparing items } & Quartzite & Flint & Obsidian \\
\hline \multirow[t]{4}{*}{ Microfracture } & Size & Medium and small & Large, medium and small & Small \\
\hline & Distribution & Continuous & $\begin{array}{l}\text { More continuous, less } \\
\text { few uneven and scattered }\end{array}$ & $\begin{array}{l}\text { Continuous } \\
\text { and overlapped }\end{array}$ \\
\hline & Termination & Feather and step & $\begin{array}{l}\text { Feather, snap, hinge, } \\
\text { and few step }\end{array}$ & Snap and feather \\
\hline & Other & Crossing the ridge & Crossing the ridge & 1 \\
\hline \multirow[t]{3}{*}{ Abrasion } & Rounding & Medium and heavy & Heavy to light & Medium and heavy \\
\hline & Striation & 1 & Few & Rare \\
\hline & Polish & 1 & Little & I \\
\hline
\end{tabular}

Tab. 2. Comparison of use-wear results from wood-working on three main raw materials.

ly medium or heavy. It was also shown that the location and degree of rounding depend on the various working techniques. Rounding caused by woodscraping appeared only on the edge ridge, while rounding results from chopping wood appeared mainly on the bulging part of the working edge. Rounding caused by drilling is heavier, especially with bidirectional rotation.

\section{Comparison of wood-working wear traces on various raw materials}

In recent years, experimental studies of wood-working use-wear on flint and obsidian have been explored by archaeologists. Thus, based on those firsthand data, we can summarise the identifiable usewear features and patterns result from wood-working on various materials.

Using flint burins for carving, scraping and drilling wood, You-Ping Wang's research (1992) showed that polish, striations, and scars appeared on the tool edge margin. The polish is bright and smooth; the burins have a banding distribution along the flat edge, but these are distributed intermittently along the uneven edge. Striations are wide and shallow; scars are relatively deep, mostly with step terminations.

Wei-Dong Li (1992) suggests that the use-wear features on flint points after carving and drilling wooden materials are: (1) Apparent and bright polish; (2) Striations, thin striations parallel to the edge caused by wood-carving, and rather small striations caused by wood-drilling; (3) A few scars and small cracks after carving, while wear traces caused by drilling consist mainly of small step scars and some large shallow scarring.

By means of low magnification, Chen Shen and Chun Chen (2001) suggest that micro-fractures on the flint tools after working on materials of medium hardness (such as dry and fresh wood) consist mainly of large and medium rolled-over shaped scars. Using 20 flint artefacts to scrape, shave, chop, saw, cut, carve, and drill dry and fresh wood, Fu-You Chen et alii (2008) demonstrate that wood-working mainly results in light rounding, while striations are caused only by chopping wood. The edge damage consists mainly of large and small scars with snap and feather terminations. Apparent rolled-over shaped scars appeared along the working edge of several specimens. Qi Fang (2009) conducted wood-working experiments with obsidian artefacts, which showed that use-wear on the working edge consists mainly of step and feather scars, mainly with continuous or overlapped distribution, while striation is rare.

To sum up, apparent use-wear appeared on all of the three materials after wood-working; the similarities and differences are (Tab. 2):

(1) Rounding on quartzite and obsidian is heavier;

(2) A few striations are observed on flint and obsidian, but not on quartzite;

(3) Most scars have feather terminations; in a few step scars, the termination, distribution and size of scars observed on the flint specimens are more complex;

(4) Scars crossing the edge ridge are observed both on quartzite and flint specimens.

On the basis of the experiments, it can be observed that the use-wear appearing on the artefacts might be due to various factors. This replicative experiment on quartzite artefacts provide us reference data for identifying use-wear features caused by wood-working. The results of this experiment are important for understanding and identifying wear traces on various materials. However, due to the limited knowledge of the physical composition and relevant analysis of our experimental specimens, we cannot reach a precise conclusion. The use-wear of archaeological artefacts is more complex, and more experiments and further studies are necessary. 
We would express our sincere appreciation to Professor Hou from the Chinese Academy of Sciences, Mr. Zemeng Yang from the Ordos Antiquity \& Archaeology Institution, Mr. Ziming Zhen from the Ordos Museum for supporting us during the experiment, and to Huihu Lian, Jun Wang, Yang Liu, Shuang Li, and Yue Lu et alii for helping us complete the experiment. We wish to extend our personal thanks to Ran Chen and Xia Yang for help. This paper was supported by the National Social Science Foundation of China (Grant No. 15CKG003), Provincial Science Foundation of Zhejiang (Grant No. LY16D020001) and Zhijiang Junior Social Science Scholars Program of Zhejiang Province.

\section{$\therefore$}

\section{References}

Chen F. Y., Cao M. M., Guang Y. and Lv J. Y. 2008. Report of wood-working experiment and use-wear analysis. In X. Gao., S. Chen (eds.), Archaeological study of lithic use-wear experiments. Science Press. Beijing: 41-60. (in Chinese)

Chen H., Hou Y., Yang Z., Zhen Z., Lian H. and Liu Y. 2014. A preliminary study on human behavior and lithic function at the Wulanmulun site, Inner Mongolia, China. Quaternary International 347: 133-138.

Chen H., Wang J., Huiru L., Mengxia F., Hou Y.-M. and Yue H. 2015. An experimental case of bone-working use-wear on quartzite artifacts. Quaternary International. http:// dx.doi.org/10.1016/j.quaint. 2015.08.086

Christian J. Z. 1978. A function analysis of "projectile points" from Yellowjacket, Colorado. Plains Anthropologist 23(79): 31-45.

Fang Q. 2009. Analysis of Micro-wears on Obsidian Artifacts in Eastern Jilin Province. Unpublished $\mathrm{PhD}$ thesis. Jilin University. Changchun. (in Chinese)

Fullagar R., Matherson M. 2013. Traceology: A summary. In C. Smith (ed.), Encyclopedia of global archaeology. Springer. New York: 73-85.

Hou Y.-M. 1992. Experimental studies of microwear analysis on stone artifacts. Acta Anthropological Sinica 11(3): 202-213.

Hou Y.-M. and 15 co-authors. 2012. The first trial excavation and significance of Wulanmulun site in 2010 at Ordos, Inner Mongolia in North China. Quaternary Sciences 32(2): 178-187.

Ho Ho Committee 1979. The Ho Ho classification and nomenclature committee report. In B. Hayden (ed.), Lithic Use-wear Analysis. Academic Press. New York.

Keeley L. 1980. Experimental Determination of Stone Tool Uses. The University of Chicago Press. Chicago.
Li W. D. 1992. Experimental studies of flint points. In Department of archaeology, Peking University (ed.), Archaeological Studies. Cultural Relics Press. Beijing. (in Chinese)

Marreiros J., Gibaja Bao J. and Bicho N. 2015. Macro and micro evidences from the past: the state of the art of archaeological use-wear studies. In J. M. Marreiros, J. F. Gibaja Bao and N. Ferreira Bicho (eds.), Use-wear and residue analysis in archaeology. Springer. Cham.

Odell G. H. 1977a. Stone tools and Mobility in the Illinois Valley: From Hunter-Gatherer Camps to Agricultural Villages. International Monographs in Prehistory. Michigan.

1977b. The Application of Micro-wear Analysis to the Lithic Component of an Entire Prehistoric Settlement: Methods, Problems and Functional Reconstructions. Unpublished PhD thesis. Department of Anthropology. Harvard University. Ann Arbor.

2004. Lithic analysis. Manuals in Archaeological Method, Theory, and Technique. Springer Science \& Business Media. New York.

Redman C. 1973. Multistage Fieldwork and Analytical Techniques. American Antiquity 38(1): 61-79.

Semenov S. A. 1964. Prehistoric Technology: An Experiment Study of the Oldest Tools and Artifacts from Traces of Manufacture and Wear (translated by Thompson M. W.). Cory, Adams \& Mackay. London.

Shen C., Chen C. 2001. Explore and practice of use-wear analysis (low-power technique): and use-analysis of lithic artefacts from the Xiaochangliang Site. Archaeology 7: 62-73. (in Chinese)

Toll H. W. 1978. Quartzite qua lithic material in archaeology: Qualities and quandaries with special reference to use-wear. Plains Anthropologist 23(79): 47-67. 
Wang Y. P. 1992. An experimental study of burins. In Department of archaeology, Peking University (ed.), Archaeological Studies. Cultural Relics Press. Beijing. (in Chinese)
Wang Z. H., Hou Y.-M., Yang Z. M., Zhen Z.-M., Liu Y., Bao L., Yang J.-G., Bai L.-Y. and Zhang L.-M. 2012. The excavation of Wulanmulun Middle Paleolithic site at Ordos, Inner Mongolia in North China. Archaeology 7: 3-13. (in Chinese) 